\title{
QUEEN'S
UNIVERSITY
BELFAST
}

\section{Management and control of invasive brown hares (Lepus europaeus): contrasting attitudes of selected environmental stakeholders and the wider rural community}

Caravaggi, A., Montgomery, W., \& Reid, N. (2017). Management and control of invasive brown hares (Lepus europaeus): contrasting attitudes of selected environmental stakeholders and the wider rural community. Biology and Environment-Proceedings of the Royal Irish Academy, 117B(2). https://doi.org/10.3318/BIOE.2017.08

Published in:

Biology and Environment-Proceedings of the Royal Irish Academy

Document Version:

Peer reviewed version

Queen's University Belfast - Research Portal:

Link to publication record in Queen's University Belfast Research Portal

Publisher rights

(c) ROYAL IRISH ACADEMY. This work is made available online in accordance with the publisher's policies. Please refer to any applicable terms of use of the publisher.

\section{General rights}

Copyright for the publications made accessible via the Queen's University Belfast Research Portal is retained by the author(s) and / or other copyright owners and it is a condition of accessing these publications that users recognise and abide by the legal requirements associated with these rights.

Take down policy

The Research Portal is Queen's institutional repository that provides access to Queen's research output. Every effort has been made to ensure that content in the Research Portal does not infringe any person's rights, or applicable UK laws. If you discover content in the

Research Portal that you believe breaches copyright or violates any law, please contact openaccess@qub.ac.uk. 
$1 \quad$ Full paper

\section{Management and control of invasive brown hares (Lepus}

\section{3 europaeus): contrasting attitudes of selected environmental}

4 stakeholders and the wider rural community

5 Anthony Caravaggi ${ }^{1,2,3 *}$, W. Ian Montgomery ${ }^{1,2,4}$, Neil Reid ${ }^{1,2,4}$

6

$7 \quad{ }^{1}$ Quercus, School of Biological Sciences, Queen's University Belfast, Belfast, BT9 7BL, UK.

$8 \quad 2$ School of Biological Sciences, Queen's University Belfast, Belfast, BT9 7BL, UK.

$9{ }^{3}$ Current address: School of Biological, Earth and Environmental Sciences, University

10 College Cork, Distillery Field, N Mall, Cork, Ireland

$11{ }^{4}$ Institute of Global Food Security (IGFS), Queen's University Belfast, Belfast, BT9 5BN, UK.

12

13 *Corresponding author: acaravaggi01@qub.ac.uk; http://arcaravaggi.co.uk/

14

15 Key words: Conservation, hares, Lepus timidus, public opinions, questionnaire survey. 


\section{Abstract}

18 Management of wildlife is often a contentious issue in which stakeholders are increasingly 19 influential. The European hare (Lepus europaeus) is a non-native, invasive species, now 20 established in Northern Ireland. It impacts the endemic Irish hare (L. timidus hibernicus), a 21 priority species of conservation concern, via competition and hybridisation to the extent that 22 control of European hares is a priority. We conducted a questionnaire survey among members of 23 Countryside Alliance Ireland $[\mathrm{CAI}]$ - an organisation that promotes rural interests, including 24 field sports - and non-members, to ascertain the contrasting attitudes to the lethal control of 25 European hares in Northern Ireland; a total of $342(20 \%)$ questionnaires were returned. We 26 hypothesised that: (i) CAI members would exhibit greater support for intervention than non27 members; and (ii) respondents in the core invasive range will differ in their outlook when compared to respondents from other zones. CAI members were more likely to be aware of the presence of the non-native species and to support lethal management. Both groups considered the threat posed to biodiversity by the European hare to be important. We conclude that members of rural interest groups may be important advocates of intervention, whilst non-members of field sports organisations may be more reluctant to support any proposed management plan involving lethal control. Active engagement to develop a mutual understanding, prior to developing management options, is crucial in ensuring long-term success. 
The European brown hare (Lepus europaeus, Pallas 1837), is not native to Ireland, having been introduced during the 1800s for field sports (Barrett-Hamilton, 1898). Populations persist in Mid-Ulster and west Tyrone (Reid \& Montgomery, 2007); despite historical records in Donegal there are no verified extant populations in the Republic of Ireland. The native Irish hare (Lepus timidus hibernicus, Bell 1837), an endemic sub-species of mountain hare ( $L$. timidus, Linnaeus 1758), is one of the few Irish mammals that pre-date the Holocene (Montgomery et al., 2014), having been isolated for at least 28,000 years (Yalden, 1999; Clark et al., 2012). Irish hare populations, which underwent a prolonged decline throughout the $20^{\text {th }}$ century (Dingerkus \& Montgomery, 2002; Reid et al., 2010), are now a high priority for conservation action. The range of the European hare in Mid-Ulster expanded threefold between 2005 and 2013 (Caravaggi et al., 2015), with the Irish hare almost entirely displaced from the invader's core range (Caravaggi et al., 2016). Furthermore, the most recent data describe extensive hybridisation between the native and the invader in the invader's range, with $32 \%$ of individuals being of hybrid origin (Prodöhl et al., 2013). The Irish hare is protected under Schedule 6 of the Wildlife (Northern Ireland) Order (1985), the Wildlife and Natural Environment Act (Northern Ireland; 2011), the Convention on Biological Diversity (UNEP, 1992), the Berne Convention (Berne, 1979) and the European Habitats Directive, Annex V (EEC, 1992). In addition, the recently ratified EU Regulation 1143/2014 on Invasive Alien Species (OJ, 2014) commits member states - in this case the United Kingdom, including Northern Ireland, and the Republic of Ireland - to identify invasive species issues and work to protect native biodiversity.

Rapid threat identification and eradication offers the most effective means of management and mitigation (United Nations Environment Programme [UNEP], 1992). However, once biological invaders become established, control and/or eradication is often difficult, if not 
impossible (Zavaleta et al., 2001). Nevertheless, invasive mammals can be eradicated, even if they are relatively well-established. Most successful removals have been undertaken on islands (Genovesi, 2005; e.g. Clout \& Russell, 2006; Donlan et al., 2007; Aguirre-Muñoz et al., 2008). A number of invasive mammal species have been successfully eradicated from all or parts of Great Britain and/or Ireland, including American mink (Neovison vison; Moore et al., 2003) and Himalayan porcupine (Hystrix brachyura; Genovesi, 2005), as well as commensal rodents, rabbits and goats from small offshore islands (e.g. Flux, 1993; Lock, 2006; Database of Island Invasive Species Eradications [DIISE], 2015). Coypu (Myocastor coypus), semi-aquatic rodents native to South America, escaped from fur farms in England and established a wild population of up to 200,000 individuals during the 1960 s before being removed during the 1980s (Baker, 2006). Similarly, the muskrat (Ondatra zibethica), was successfully eradicated from Ireland (Fairley, 1982) and Great Britain (Warwick, 1941) by 1936 whilst introduced roe deer (Capreolus capreolus) were eradicated from Ireland in the early $20^{\text {th }}$ century (Fairley, 1984, 2001).

Wildlife control, however, has become a contentious issue in which the public are increasingly influential. A lack of public support can impact the efficacy of eradication campaigns, reducing the probability of success (sensu Enticott, 2015; McCagh et al., 2015). It is increasingly important, therefore, to garner public support for initiatives involving the removal or translocation of wildlife (Bremner \& Park, 2007; Philip \& Macmillan, 2005; Sijtsma et al., 2012). Eradication programmes in particular, can often be perceived as objectionable, and ethically challenging (Manchester \& Bullock, 2001; Bertolino \& Genovesi, 2003). However, while the views of professionals (i.e. ecological experts) and the public may differ with regards to invasive species, there are also many commonalities (Roux et al., 2006; Buijs \& Elands, 2013; Fischer et al., 2014). Thus, the assumptions of the 'deficit-model', wherein the public are described in general terms as a homogenous body 
87 requiring education (usually by scientists) are increasingly seen as antiquated and limiting

88 (Fischer et al., 2014). It is essential, therefore, that decision makers and those implementing population management policies have a sound understanding of different perspectives on invasive species issues, thus facilitating the development of socially acceptable solutions. Discussion and transparency between all parties prior to the application of control programmes may offset what might otherwise be perceived as unpalatable management prescriptions, and mitigate against potential conflict (Fischer et al., 2014).

Given the increasing role of the public in participatory decision making and the legal requirements for government in both political jurisdictions of Ireland to address invasive species issues, it is important that decision makers have a sound understanding of public attitudes on which they can base management decisions. We aimed to ascertain the degree of awareness and explore local views on the management of the European hare in Northern Ireland. Specifically, we tested the hypothesis that members of Countryside Alliance Ireland (CAI) - an organisation that promotes rural interests, including field sports (e.g. hunting, shooting (see www.caireland.org)) - may exhibit greater support for intervention than nonmembers. We also compared responses across three geographic zones: native species allopatry; and the invasive species' peripheral and core ranges. We hypothesised that respondents in the core range where European hares have almost entirely displaced the native species will differ in their outlook to respondents in other zones. The results presented are likely to inform the development and adoption of government policy and any subsequent management programme for the European hare in both political jurisdictions of Ireland, and could act as a model for the management and/or control of comparable invasive species elsewhere. 
112 A questionnaire (Supplementary Information (SI) 1) was used to assess public awareness of 113 the European hare as an invasive species, and the willingness of the public to support direct, 114 interventionist management. Questions were descriptive (i.e. more than two options were provided, or a textual response was required) or discrete (i.e. only two options were provided: yes or no). A total of 1,680 questionnaires were issued by post in August 2014, to two groups across Northern Ireland: CAI members, and non-members. No inducements were offered to encourage responses. The CAI defines itself as "promot[ing] the interests of rural people, including all field sports (hunting, shooting, fishing, falconry, ferreting, coursing, stalking etc), sensible wildlife management, and wider countryside concerns such as jobs, landscapes and freedoms". Non-members were defined as randomly-selected participants (see below) whose address did not correspond with that of any then-current CAI member. Survey participants were further selected according to their geographic location relative to minimum convex polygons $(\mathrm{MCP})$ that described the core $(50 \%$ occurrence) and peripheral $(100 \%$ occurrence) range of the invasive European hare in 2012-13, with the zone of native Irish hare allopatry occurring outside the peripheral polygon (Fig. 1a). MCPs were mapped using ArcGIS 10.3.1. For further details on how these zones were delineated, see Caravaggi et al. (2015). In total, 280 questionnaires were sent to each of 6 sub-groups (Fig. 2).

Respondents were randomly selected within $5 \mathrm{~km}$ radii of a number of focal settlements, within each zone of invasion, so as to provide a widespread geographical sample (Fig. 1a). The closest dwelling to randomly generated waypoints within each $5 \mathrm{~km}$ buffer was identified using Google Maps, and the address recorded. Questionnaires were distributed by CAI to randomly-selected members within the same settlements so as to comply with the Data Protection Act and issues regarding the protection of names, private details and addresses. 
Thus, it was not possible to account for demographic factors such as age, gender and income.

The number of focal settlements per zone was defined by two factors. First, settlements were required to have a population $>400$ to ensure presence of CAI members (whilst avoiding large towns or cities of $>12,000$ ). Mean population size per settlement per zone were comparable, with $2,899 \pm 1,833$ people in the invader's core range, $2,749 \pm 1,142$ in the invader's peripheral range and 2,683 \pm 553 people in the zone of native allopatry. The second factor was to ensure that the total number of CAI members per zone was in relative proportion to the mean population. The number of potential recipient settlements in the core and peripheral zones was limited by the small geographic extent of the invasive range. Thus, four settlements were selected in the invader's core range, nine in the invader's peripheral range and thirteen in the zone of native allopatry (Fig. 1a). Agriculture, Environment and Rural Affairs (DAERA), the agency that would be responsible for sanctioning any invasive species population intervention. Each questionnaire was given a unique reference number. All respondents were anonymous unless they elected to provide contact details. Electronic questionnaires were unsuitable for our purposes given the rural locations and lack of broadband internet for many respondents. Questions 1-7 ascertained the respondent's occupation and general attitudes towards hares and were followed by an information page regarding the threat posed by the invasive species (based on peer-reviewed published information), thereby ensuring that respondents were able to place subsequent questions in an appropriately informed context. Questions 8-20 clarified prior awareness of invasive species issues, examined attitudes post-information provision, and sought opinion of population management i.e. whether participants would support government intervention to benefit the native species. Question 20 was deliberately circular, repeating a query on willingness to support a cull (Q13b) but framed in the context of supporting a government 
decision. These responses were used as an indicator of respondent consistency, or lack thereof. Differences between responder groups were assessed using binomial tests where a $p$ value is derived from comparing observed and expected values for given sample sizes. An Analysis of Variance (ANOVA) test, with Tukey post-hoc tests, was used to determine differences in levels of support for lethal culling between respondent groups in each of the three study zones. Confidence intervals of $95 \%$ around percentage data were established by calculating the Wilson interval without correction for continuity (Wilson, 1927, as described in Newcombe, 1998). Pearson's correlation coefficient was used to investigate relationships between certain questions (e.g. Q13b and Q17). Textual responses ('Additional comments',

SI 1) were analysed based on their perceived support for lethal management, or lack thereof (applied categories: yes; no; unsure).

A General Linear Model (GLM) was constructed with support for lethal management (0/1)

172 fitted as the dependant variable using a binomial error structure and a logit link function. Six 173 questions $(10 ; 13 \mathrm{a} ; 15 ; 18 ; 19)$ were omitted as fewer than $90 \%$ of respondents completed the answers, substantially reducing the sample size available for analyses $(n=215-307)$. The effect size of each variable in the top model (see SI 2) was plotted and variables ranked by their effect. The Area Under the Curve (AUC) of the Receiver Operating Characteristic (ROC) curve was used to assess the performance of the single best approximating model. All statistical analyses were run in $\mathrm{R}$ (R Core Team, 2017) using the packages leaps (Lumley, 2009), MuMIN (Barton, 2015) and pROC (Robin et al., 2011). 
A total of 342 questionnaires were returned (20\% response rate), of which 140 were from CAI members (41\%), and 202 were from non-members (59\%). Response rates from nonmembers were comparable between the zones of invasion with $35 \%$ in Irish hare allopatry, $34 \%$ in the invader's periphery and $31 \%$ in the invader's core range. In contrast, response rates from CAI members were significantly higher within the invader's core range $(41 \%)$ compared to the invader's periphery $(31 \% ; p<0.001)$ and the zone of Irish hare allopatry $(28 \% ; p<0.001)$. Landowners accounted for $77 \%$ of non-members, with $91 \%$ having observed hares, whilst landownership was lower among CAI members $(51 \% ; p<0.001)$, of whom 99\% had observed hares (Table 1).

CAI members were significantly more likely to provide textual comments with their responses $(38 \%)$ compared to non-members $(13 \% ; p<0.001$; SI 3$)$. The majority of comments concerned lethal management of the European hare (68\% vs 59\% of CAI members and non-members respectively), of which $44 \%$ of respondents indicated their opposition, irrespective of affiliation; $25 \%$ of CAI member respondents would support a cull (vs $12 \%$ of non-members), and $31 \%$ were unsure (vs $44 \%$ of non-members).

The majority of respondents perceived that the hare population (both species) had declined during the last 50 years ( $66 \%$ of respondents), while $49 \%$ maintained that this decline was ongoing during the last 5 years (Fig. 3). The most notable differences in opinion were held by those who perceived population trajectories to be increasing during the last 50 years, with $19 \%$ of CAI members, compared to $8 \%$ of non-members $(p<0.001)$. CAI members were less likely to consider hares an agricultural pest than non-members. Respondents from all three zones of invasion (including Irish hare allopatry) claimed to have observed European hares, contradicting the known (observed) range of the invasive species (Fig. 1b). 
CAI members were significantly more likely to have been aware of the presence of the

206

207

208 invasive species prior to receipt of the questionnaire than non-members $(62 \%$ vs $29 \%$ respectively; $p<0.001$ ), and to support active petitioning of government for control of the invader than non-members ( $60 \%$ vs $37 \%$ respectively; $p<0.001$; Table 1$)$. Levels of support for lethal control differed between the two groups, with CAI members being more likely to support culling than non-members (66\% vs 40\% respectively; $p<0.001$; Fig. 4a; Table 1). An ANOVA with Tukey post-hoc tests captured significant differences between the opinions of respondent groups between the zones of invasion. CAI members resident in the invader's peripheral range were significantly more likely to support a cull than non-members anywhere within the invader's range (core or periphery), whilst CAI members in the zone of native allopatry were more likely to support a cull than non-members (Fig. 4b).

CAI members were significantly more likely to hunt than non-members ( $91 \%$ vs $21 \%$ respectively), with support for lethal culling being strongly correlated with hunting activity ( $r$ $=0.54, p<0.001)$. A large proportion of respondents who owned or rented land would permit a hare population survey to be carried out (83\%; Fig. 5). However, those with smaller properties ( $<30$ ha) were less likely than those with larger properties (30-100 ha and $>100$ ha) to permit European hares to be lethally removed if they were found to be present $(42 \% \mathrm{vs}$ $56 \%$ respectively; $p=0.007$; Fig. 5). Both groups (i.e. members and non-members) responded similarly to questions relating to their concern for the conservation of biodiversity with $82 \%$ of CAI members and $88 \%$ of non-members 'concerned'. Similarly, both groups had comparable willingness to support impact mitigation ( $81 \%$ vs $76 \%$ respectively) and/or habitat management for the benefit of the native species ( $78 \%$ vs $80 \%$ respectively; Table 1$)$.

$$
\text { Responses to questions } 13 \mathrm{~b} \text { (support for lethal management of the European hare) and } 20
$$
(support for a government decision to cull) demonstrated considerable respondent 
229 consistency, with $82 \%(n=138)$ of CAI members and 90\% $(n=123)$ of non-members 230 providing consistent answers. The single best approximating model for support of lethal 231 management was influenced by the respondent's willingness (or lack thereof) to petition 232 government (Q14), and whether the respondent supported management (Q12), hunted (Q17), 233 was aware that there were two species of hare in Northern Ireland (Q8), and was concerned 234 with the conservation of biodiversity (Q3; Table 2; Fig. S2.1). 
237 This study is the first quantitative investigation of public attitudes to management of the 238 European hare population in Northern Ireland. The response rate to our survey (20\%) was 239 considerably lower than the mean response rate $(52 \pm 3 \%)$ reported from a meta-analysis of 24082 postal ecological surveys (White et al., 2005). A stratified random sampling procedure was used to minimise bias, but our data have inherent limitations with regards to demographic representation; a common problem in questionnaire-based research (Sapsford, 1999). The lower than anticipated response rate may reflect unquantified factors, including: low motivation of targeted households; apathy with regards to wildlife management and/or conservation; lack of identification with a remote government and/or study; a lack of engagement (e.g. disposal of the questionnaire); and, distrust of authority figures (i.e. government, scientists, etc.). Opinions on wildlife control methods are also likely to vary according to gender, age, income and education (Koval \& Mertig, 2004; Bremner \& Park, 2007; Enticott, 2015). This was probably also true in the present study, but demographic data were lacking due to the necessity to anonymise questionnaires (at the request of CAI) for data protection.

Fraser et al. (2014) suggested that stakeholders with a vested interest in their environment, such as voluntary participants, or those with an economic interest such as farmers and land managers that subscribe to agri-environment schemes (e.g. the Environmental Farming Scheme; DAERA, 2017), may be more willing to actively help protect local biodiversity. However, public opinion with regard to non-native species is not necessarily predictable (Koval \& Mertig 2004); while the reasoning of experts and the public share common linkages, they do not necessarily arrive at the same decisions (Buijs \& Elands, 2013; Fischer et al., 2014). Hence, the acceptability of management prescriptions is likely to vary on a caseby-case basis. This is reflected in the present study, with both groups being in agreement on 
many questions, but differing in their support for lethal management (66\% CAI vs $40 \%$ of non-members). The responses of non-members to potential management options suggest that lethal control may only be considered acceptable once other methods have failed (Dandy et al., 2011, 2012). However, Enticott (2015) suggests that public support may be influenced by framing the issue appropriately, in this case, the protection of a unique, endemic species.

The lowest levels of support for lethal control in both respondent groups were found in the invader's core range, where European hares occur at a high density to the near total exclusion of the Irish hare (Caravaggi et al., 2016). This raises the possibility that exposure to the invader does not necessarily confer support for lethal management (Dandy et al., 2011). Indeed, the perception of the species may depend not on its nativeness, or lack thereof, but on the composition of the local ecological assemblage. Therefore, control or eradication of the European hare may not be perceived as necessary in the invasive core range where the native species is largely absent. This rationale may be interpreted in terms of functionalism (i.e. the retention of ecosystem processes) versus compositionalism (i.e. maintaining species assemblages; Callicott et al., 1999; Gillson et al., 2011) whereby the local ecosystem still has hares, that may carry out the same ecological functions of grazing and being key prey, and at a higher density than before (Reid \& Montgomery, 2007; Caravaggi et al., 2016). Differences in the acceptability of lethal control may also depend on the type and volume of information available on invasive species and conservation options for the native post-removal (e.g. natural recolonization, anthropogenic translocations). To address these questions, it would be beneficial to engage in a dialogue with stakeholders so as to arrive at a mutual understanding, prior to considering management options (sensu Fischer et al., 2014).

The picture may be complicated when sympatric native and invasive species are phenotypically similar, as untrained observers may be unable to differentiate between the two (COI, 2009). Indeed, this seems to be the case in the present study; most European hare 
records $(n=79 ; 75 \%)$ were returned within the invader's range in Mid-Ulster, while the

287

288

289

290

291

292

293

294

295

296

297

298

299

300

301

302

303

304

305

306

307

308

309

remainder were distributed across Northern Ireland, in localities far beyond their known range, where they were previously undetected by surveyors (Reid \& Montgomery, 2007; Caravaggi et al., 2015, 2016; Fig. 1b). It is possible that European hares have been observed by the public where they were missed by surveyors; hare survey data from nocturnal distance sampling are spatially broad, but temporally narrow, with observations being affected by undulating terrain, and surveys were not comprehensive. However, while a number of putative European hare observations have been recorded across Ireland, none have been substantiated (Reid, 2011; Caravaggi, 2012-15, pers obs). Thus, we can be relatively confident that most records from outside the known range in the present study were based on inaccurate observations/recollections and species misidentification.

Irish hare populations declined dramatically throughout the $20^{\text {th }}$ century (Dingerkus, 1997; Dingerkus \& Montgomery, 2002; Reid, 2006; Reid et al., 2006), but stabilised during the early $21^{\text {st }}$ century at low densities (Reid et al., 2007). European hares may have been introduced to Mid-Ulster as recently as the 1970 s with subsequent population and range expansion, most notably between 2005 and 2012/13 (Caravaggi et al., 2015). Hare population densities are up to eight times higher in the invasive core range than in areas of Irish hare allopatry, with over 90\% being European-like (Caravaggi et al., 2016). Thus, we might have expected questionnaire respondents to corroborate these observations, particularly within the invasive core range. However, while more respondents considered hare numbers to have stabilised in the last 5 years $(33 \%)$ when compared to the last 50 years $(22 \%)$, there was no difference in the number of respondents who perceived a short-term population increase in the core range of the European hare. Public observations, therefore, while undoubtedly valuable in providing contemporary occurrence records for wildlife, may be less reliable 
when it comes to assessing more subtle events such as population fluctuations, thus highlighting the requirement for accurate recording and systematic research.

The interest in the conservation of biodiversity among both respondent groups reflected similar attitudes across Europe (Thornton, 2009; European Commission, 2015) and was coupled with a concern for the native Irish hare. However, this did not translate into support for lethal culling amongst respondents who owned land, presenting a potential impediment to the implementation of management programmes (Susskind \& Cruickshank, 1987, cited in Decker et al., 1996). Any eradication attempt that cannot access the full range of the species is unlikely to succeed and, hence, should be sensitive to the need for considered engagement of landowners. Eradication is not the only option available to decision-makers. The current invasive range, while expanding, is still relatively small (Caravaggi et al., 2015) and is constrained by Lough Neagh to the east and the unsuitable heather moorland habitat of the Sperrin mountain range to the west which present potential barriers to longitudinal dispersal. Hence, the European hare could be effectively contained within its current invasive range by lethal control along the northern and southern range edge margins. However, the zone of sympatry between the European and Irish hares is extensive; issues of species discrimination in-situ would remain and dispersing Irish-like first-generation (F1) hybrids would continue to threaten the genetic integrity of the Irish hare. Habitat management aimed at improving the landscape for native hares, to the detriment of the invader, represents a possible alternative to lethal management but is unlikely to be effective in controlling the invasive population given their ecological similarity to the native species (Reid \& Montgomery, 2007; Caravaggi et al., 2015).

In conclusion, the fundamental interest in natural heritage, conservation, and the welfare of the Irish hare demonstrated by the majority of respondents suggests that an effective, acceptable means of control and/or eradication of the European hare in Ireland may be 
335 possible. Moreover, a small number of interrelated factors may be relevant in determining 336 how an individual responds to future invasive species management proposals. CAI members, 337 many of whom hunt and shoot (i.e. own a gun licence), represent a huge potential resource 338 with around 3,500 local members (Lyall Plant, pers comm), approximately half of whom 339 (52\% of affiliated respondents) may be willing to participate in a voluntary coordinated 340 control or eradication programme In addition, support from organisations such as CAI may 341 help persuade other groups with similar interests and goals - for example, the British 342 Association for Shooting and Conservation (BASC) or the Game and Wildlife Conservation 343 Trust (GWCT) or local private gun clubs (e.g. the Megargy and District Game and 344 Conservation Society) - to become actively engaged. The level of support for lethal management among non-members and the reluctance of landowners to permit access to their 346 land present immediate obstacles. Hence, the first steps towards making any management 347 process a reality involve outreach and engagement with stakeholders. This study provides vital data which will be of considerable value to decision-makers in Northern Ireland and is 349 an example for similar initiatives elsewhere within the global invasive range of European hare or other invasive species. 
353 We are grateful to Declan Looney who acted as NIEA Client Officer and commented on the 354 questionnaire design and a draft of this manuscript, Lyall Plant and Countryside Alliance 355 Ireland for their willingness to participate in this study, supporting questionnaire distribution, 356 and all those who responded to the survey. We thank the editor and reviewers, whose 357 comments and suggestions were instructive in improving this manuscript. None of the views 358 expressed in this paper are the policy or views of either the Department of Agriculture, 359 Environment and Rural Affairs (DAERA) or Countryside Alliance Ireland.

360

361 Funding: This project was funded by the Natural Heritage Research Partnership (NHRP)

362 between then Northern Ireland Environment Agency (NIEA) and Quercus, Queen's 363 University Belfast (QUB). 
Table 1. The number of responses, and the percentage of those responses which were positive, to each question in a survey of attitudes to lethal management of invasive European hares in Northern Ireland. Where questions are accompanied by an asterisk (13c), all responses were positive, thus percentages were calculated relative to the parent question (13b). Total positive responses to $13 \mathrm{c}$ for both groups exceeded the number of positive responses for $13 \mathrm{~b}$ within which they are nested as many respondents selected more than one option. Conversely, a number of non-members did not select an option in 13c. See Supplementary Information 1 for full question text.

\begin{tabular}{|c|c|c|c|c|c|}
\hline \multirow{2}{*}{\multicolumn{2}{|c|}{ Question }} & \multicolumn{2}{|c|}{$\begin{array}{l}\text { Countryside Alliance } \\
\text { Ireland members }\end{array}$} & \multicolumn{2}{|c|}{ Non- members } \\
\hline & & $\begin{array}{c}\text { Number of } \\
\text { responses }\end{array}$ & Yes $(\%)$ & $\begin{array}{l}\text { Number of } \\
\text { responses }\end{array}$ & Yes $(\%)$ \\
\hline 1 & Landowner/user & 140 & 51 & 202 & 77 \\
\hline 2 & Farmer & 140 & 24 & 202 & 42 \\
\hline 3 & Concerned with conservation of biodiversity & 134 & 88 & 191 & 82 \\
\hline 4 & Seen hares in NI & 140 & 99 & 201 & 91 \\
\hline 5 & Consider hares to be pests & 140 & 9 & 201 & 17 \\
\hline 6 & Impression of hare numbers ( $<=50$ years) & 139 & See Fig. 3 & 200 & See Fig. 3 \\
\hline 7 & Impression of hare numbers ( $<=5$ years $)$ & 140 & See Fig. 3 & 200 & See Fig. 3 \\
\hline 8 & Aware of two species of hare in NI & 139 & 62 & 202 & 29 \\
\hline 9 & Seen a European hare in Northern Ireland & 139 & 51 & 202 & 19 \\
\hline 10 & Seen a European hare on their land & 69 & 32 & 153 & 19 \\
\hline 11 & The threat posed by the European hare is important & 135 & 64 & 194 & 65 \\
\hline 12 & Support management aimed at impact mitigation & 140 & 81 & 193 & 76 \\
\hline \multirow[t]{7}{*}{13} & Support either of the following: & & & & \\
\hline & a) Habitat management to benefit the Irish hare & 101 & 78 & 168 & 80 \\
\hline & b) Lethal culling of the European hare & 139 & 66 & 184 & 40 \\
\hline & c) If so, which method: & & & & \\
\hline & Netting* & 62 & 45 & 53 & 29 \\
\hline & Trapping* & 40 & 29 & 33 & 18 \\
\hline & Shooting* & 72 & 52 & 49 & 27 \\
\hline 14 & Sign a petition to lobby for action & 139 & 60 & 191 & 37 \\
\hline \multirow[t]{2}{*}{15} & $\begin{array}{l}\text { a) Allow their land to be surveyed for European } \\
\text { hares }\end{array}$ & 72 & 82 & 143 & 72 \\
\hline & $\begin{array}{l}\text { b) Allow European hares to be culled on their land, } \\
\text { if found }\end{array}$ & 74 & 53 & 115 & 46 \\
\hline 16 & Member of conservation organisation & 139 & 13 & 198 & 4 \\
\hline 17 & Hunt/shoot & 137 & 91 & 186 & 21 \\
\hline 18 & Actively support a cull via direct involvement & 138 & 51 & 175 & 22 \\
\hline 19 & Allow a cull on their land (no direct involvement) & 70 & 47 & 130 & 41 \\
\hline 20 & $\begin{array}{l}\text { Support Governmental decision to cull European } \\
\text { hares }\end{array}$ & 139 & 65 & 183 & 54 \\
\hline
\end{tabular}


Table 2. Relative importance of explanatory variables in the best approximating model explaining support of lethal management of the European hare in Northern Ireland. $\Sigma \omega_{i}=$ sum of Akaike weights; $p$ values are denoted as $* p<0.05, * * p<0.01$, and $* * * p<0.001$. Question numbers are given in parentheses (see Supplementary Information 1 for full text). For all variables including in model averaging, see SI 2.

\begin{tabular}{lcrll}
\hline \multicolumn{1}{c}{ Question } & $\boldsymbol{\Sigma} \boldsymbol{\omega}_{\boldsymbol{i}}$ & Effect size $(\boldsymbol{\beta} \pm$ SE) \\
\hline Would petition government (Q14) & 1.00 & 0.57 & $\pm 0.05^{* * *}$ \\
Support management (Q12) & 1.00 & 0.18 & $\pm 0.06^{* *}$ \\
Hunt (Q17) & 1.00 & $0.16 \pm 0.05 * *$ \\
Aware of two hare species (Q8) & 0.57 & $-0.07 \pm 0.05$ \\
Conservation concern (Q3) & 0.55 & $-0.09 \pm 0.06$ \\
\hline
\end{tabular}


Fig. 1. a) The distribution of settlements throughout Northern Ireland within which randomly-selected residents were surveyed using questionnaires. b) Locations of European hare records $(n=106)$ reported by questionnaire respondents, scaled according to the numbers of respondents or who claimed to see European hares. The dashed-line polygons denote the invasive European hare's core range (inner 50\% Minimum Convex Polygon or $\mathrm{MCP}$ ), peripheral range (outer $100 \% \mathrm{MCP}$ ), and a small remnant population (5 individuals identified in 201213; unpublished data from surveys published as Caravaggi et al., 2015) in West Tyrone.

Fig. 2. The distribution of questionnaires to two responder groups across three geographic zones describing European hare occurrence in Northern Ireland. CAI $=$ Countryside Alliance Ireland. $n_{i}=$ number of questionnaires per group. For details on how zones were delineated, see Caravaggi et al. (2015).

Fig. 3. Public perceptions of hare population temporal trends over (a) the last 5 years $(2009-2014)$ and (b) the last 50 years (1964 - 2014) throughout Northern Ireland for both the native Irish and invasive European hares. The percentage of respondents answering 'decreasing' (black), 'no change' (grey) and 'increasing' (white) within the three zones of invasion: i) native species allopatry, ii) the invasive species' peripheral range and iii) the invader's core range are presented for Countryside Alliance Ireland members (CAI) and non-members (NM). Horizontal black lines represent the mean of those answering 'decreasing'.

Fig. 4. Percentage $\pm 95 \%$ confidence limits of Countryside Alliance Ireland members (CAI; grey) and nonmembers (NM; white) who (a) support lethal culling of the invasive European hare in Northern Ireland and (b) split between each zone of invasion. Superscript letters above the bars represent significant differences $(p<0.05)$ between groups using Tukey post-hoc tests: A $>\mathrm{a} ; \mathrm{B}>\mathrm{b}$.

Fig. 5. Percentage $\pm 95 \%$ confidence limits of respondents who own or rent land who would allow a survey to be carried out on their land (grey), and would allow lethal management of the European hare to be carried out on their land (white) if the species was found to be present. 


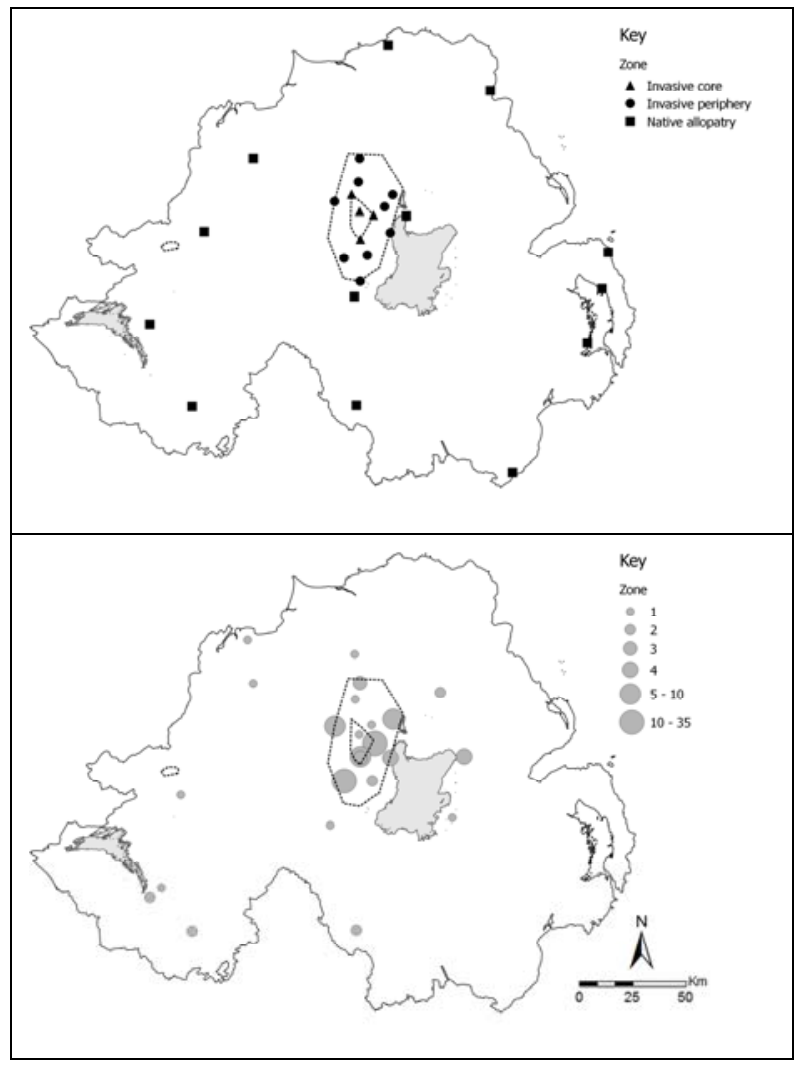

Figure 1. 


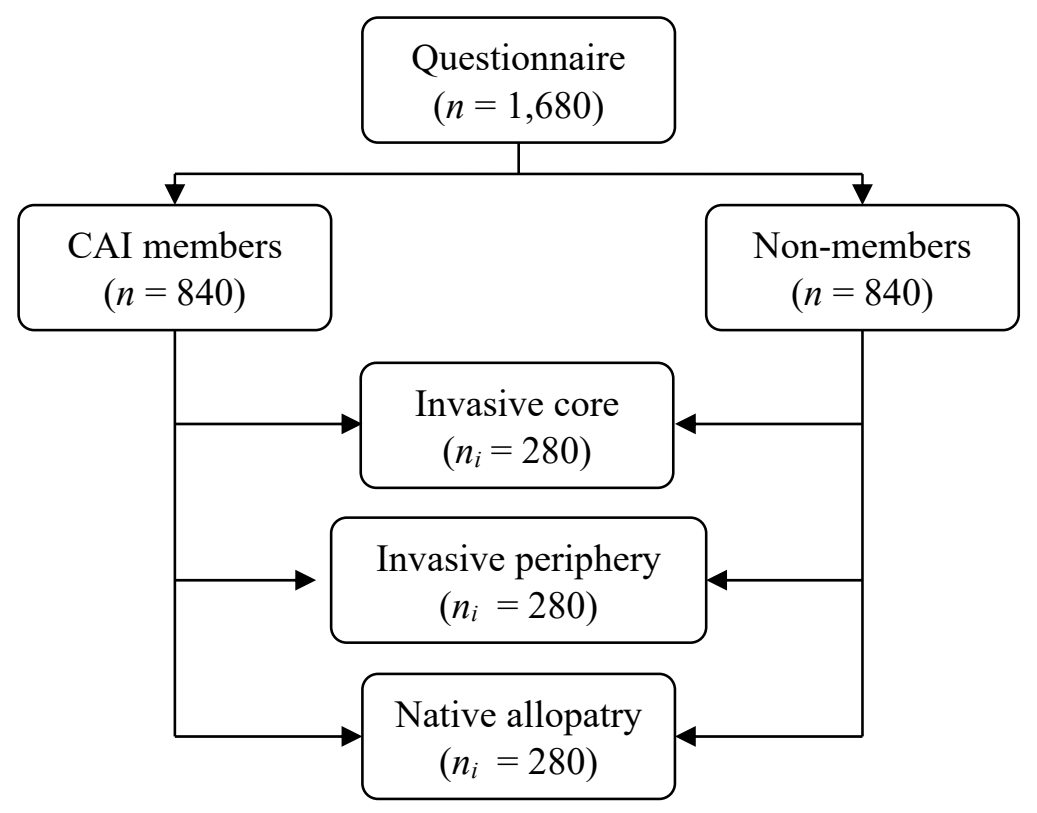

Figure 2. 


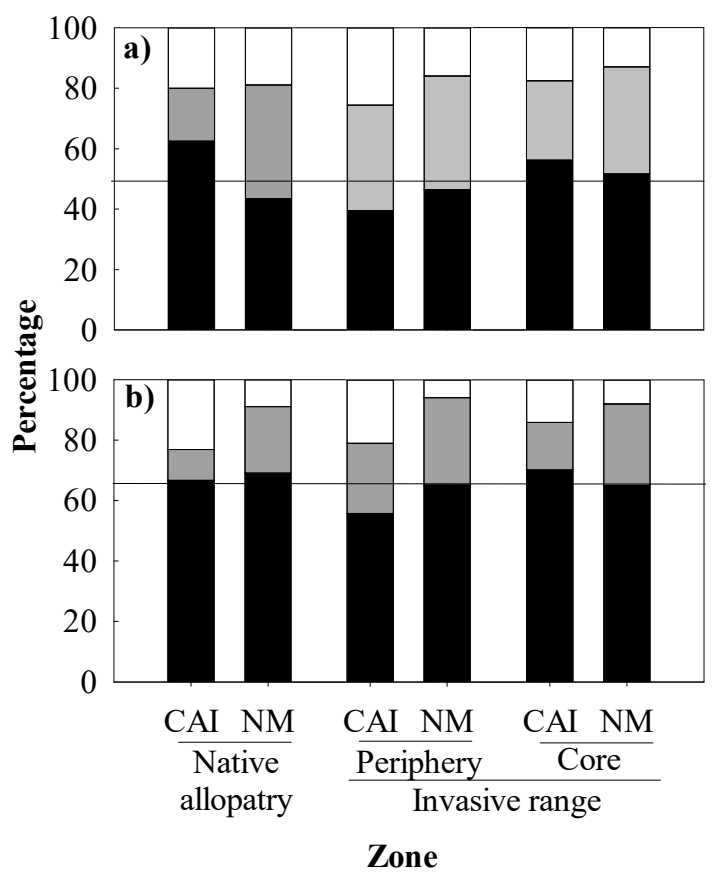

Figure 3. 


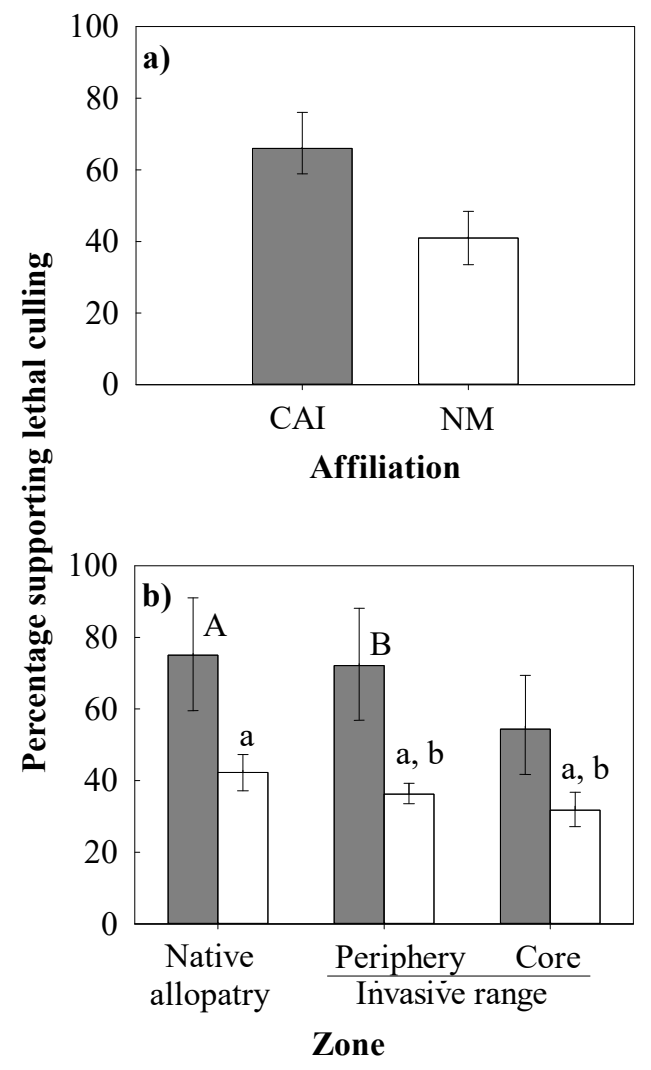

Figure 4. 


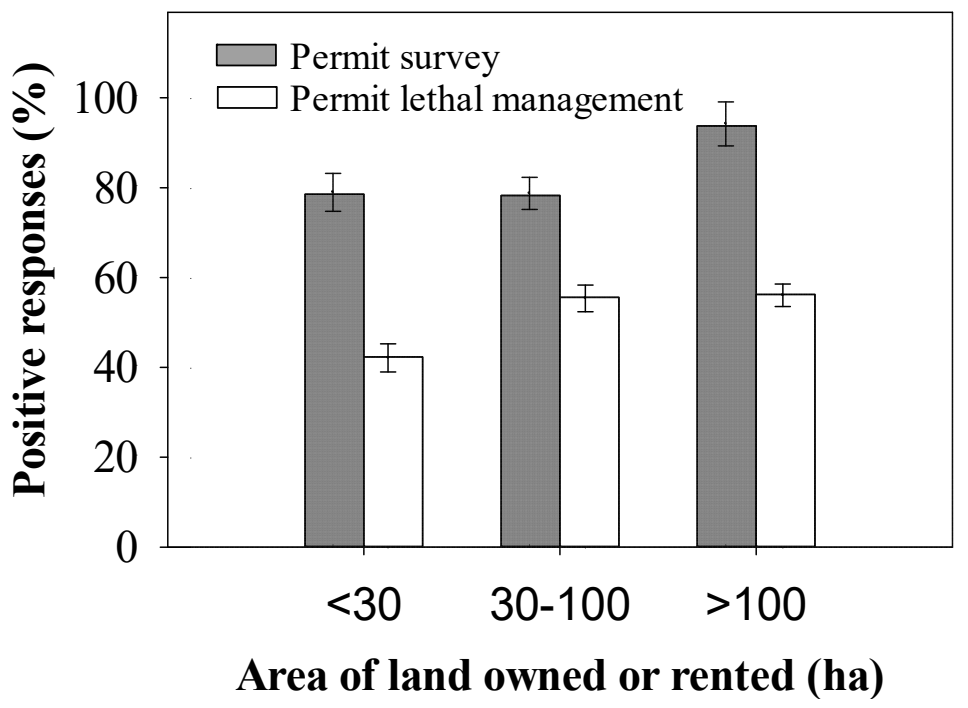

Figure 5. 
Biology and Environment

\section{Supplementary information 1}

\section{Management and control of invasive brown hares (Lepus europaeus): contrasting attitudes of selected environmental stakeholders and the wider rural community}

Anthony Caravaggi ${ }^{1,2,3 *}$, W. Ian Montgomery ${ }^{1,2,4}$, Neil Reid $^{1,2,4}$

\footnotetext{
${ }^{1}$ Quercus, School of Biological Sciences, Queen's University Belfast, Belfast, BT9 7BL, UK.

2 School of Biological Sciences, Queen's University Belfast, Belfast, BT9 7BL, UK.

${ }^{3}$ Current address: School of Biological, Earth and Environmental Sciences, University

College Cork, Distillery Field, N Mall, Cork, Ireland

${ }^{4}$ Institute of Global Food Security (IGFS), Queen's University Belfast, Belfast, BT9 5BN, UK.

* Corresponding author: acaravaggi01@qub.ac.uk
} 


\section{Questionnaire on hares in Northern Ireland}

Reference number:

Date:

\section{Contact details (OPTIONAL)}

Name:

Address:

Telephone number:

Email:

1. a) Do you own or rent land for agriculture, forestry or some other purpose?

b) Specify which:

Yes $\quad \square \quad$ No

$\square$

Agriculture

Forestry

Other, please specify

c) Approximately how much land do you own/rent?

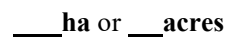

2. a) Are you an active farmer?

b) If yes, what is the main focus of your farm?

Yes

$\square \quad$ No

Beef cattle

Dairy cattle

Sheep

Arable

Mixed

3. Are you concerned with the conservation of biodiversity?

Yes

No

4. a) Have you seen hares in Northern Ireland?

b) If yes, when was your most recent sighting?

Yes $\square \quad$ No

0 - 6 months ago

6 months - 1 year ago

$1-2$ years ago

$2+$ years ago

Yes

$\square \quad$ No

6. What is your impression of hare numbers during your lifetime

No change

(up to last 50 years)?

Increasing

Decreasing

7. What is your impression of hare numbers over the last 5 years?

No change

Increasing

Decreasing 


\section{Please read this information before completing the rest of the questionnaire}

The native Irish hare (Lepus timidus hibernicus) is one of the characteristic animals of Ireland having been isolated here for at least 25,000 years. Irish hare populations have undergone a population decline throughout the $20^{\text {th }}$ century. As a result, it is a high priority for conservation action and is subject to national and international legislation which aim to protect native biodiversity.

The invasive European brown hare (Lepus europaeus), also known locally as the 'English' or 'thrush' hare, is not native to Ireland having been introduced in the 1800s for field sports. They are typically found on flatter, drier land, particularly areas with some arable agriculture (i.e. crops). In Northern Ireland, they are found in mid-Ulster and west Tyrone (see map).

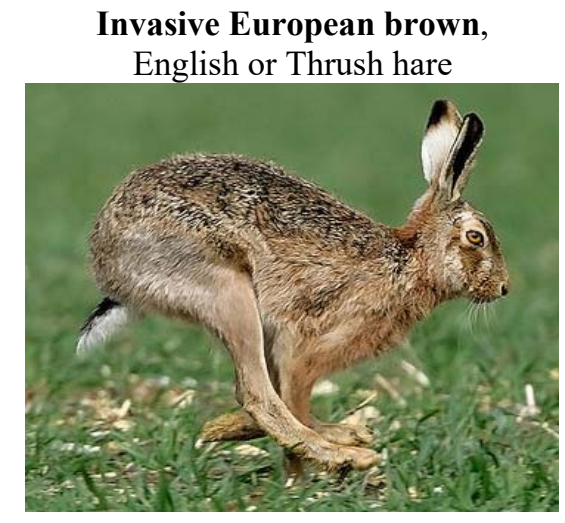

Features:

Sandy brown

Mottled coat

Angular head

Black tail

Ears longer than head

Black tips to ears very distinct
Native Irish hare

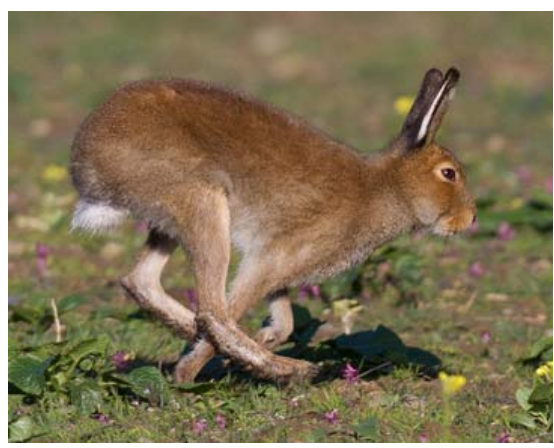

Russet reddy brown

Smooth colouration

Rounded head

White tail

Ears same length as head

Black tips to ears not distinct

European hares were introduced to Sweden in the 1800 s. Being bigger than the native mountain hares, they were able to out-compete the natives for food and mates. The mountain hare is now locally extinction throughout much of southern Sweden.

The Irish hare is bigger and more adaptable than its other mountain hare relatives so may provide stiffer opposition to invasion by European hares. However, studies have shown than the range of the European hare in mid-Ulster is expanding and that some areas show a considerable amount of hybridisation (offspring produced from both species interbreeding).

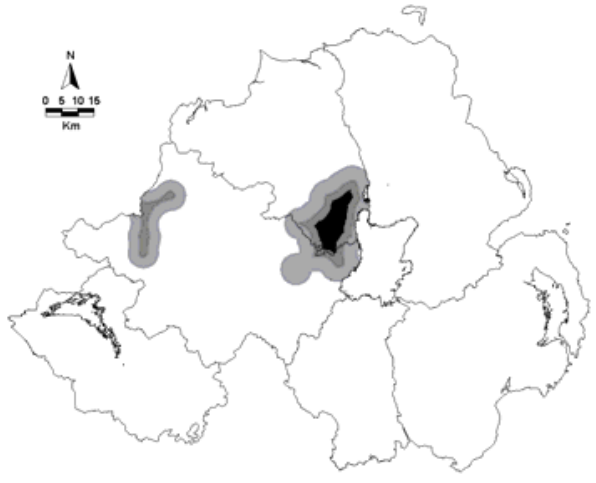

Map showing the distribution of European hares in Northern Ireland.

The European hare presents a significant threat to the security of the Irish hare. Europeanlevel legislation requires the UK and Ireland to address issues of invasive species and some have called for the invader to be controlled or eradicated in Northern Ireland. 
8. Were you previously aware that there were two kinds of hare in Northern Ireland?

9. a) To the best of your knowledge, have you ever seen a European brown hare in Northern Ireland?

Yes

b) If yes, where (nearest town)?

10. a) If you are a landowner or manager, have you ever seen European hares on your land?

b) If yes, where (nearest town)?

c) If yes, when was your most recent sighting?

Yes

No

0 - 6 months ago

6 month- 1 year ago

$1-2$ years ago

$2+$ years ago

11. Do you personally consider the threat posed by the European hare to the native Irish hare to be important?

Yes

No

12. Would you support management aimed at mitigating the impact of the European hare?

Yes

13. Do you support the notion of either of the following:
a) Non-lethal habitat management to benefit the Irish hare?
b) Lethal culling to control or eradicate the European hare
c) If so, which method would you support (tick all that apply):

$\begin{array}{lll}\text { Yes } & \square & \text { No } \\ \text { Yes } & \square & \text { No } \\ \text { Shooting } & & \\ \text { Netting } & & \\ \text { Trapping } & & \end{array}$

14. Would you actively support a cull by signing a petition to lobby Government for action? (note that you will not be asked to actually do so - this is only hypothetical)

Yes

No

15. a) If you are a landowner or manager would you allow your land to be surveyed for European hares?

Yes

No

b) If yes, and European hares were found to be present would you permit them to be culled by (planned and responsible) shooting?

Yes

No

16. Are you a member of a conservation organisation, specifically not affiliated with shooting e.g. the Ulster Wildlife Trust?

Yes

No 
17. a) Do you hunt/shoot?

b) If yes, what do you hunt/shoot?

Yes $\quad \square \quad$ No

Game birds

Rabbits

Wildfowl

Fishing/angling

Other

(please specify below)

18. Would you actively support a cull by participating in coordinated shooting of European hares (under direction) either on your own land or land on which you have permission?

If you would not actively participate in coordinated shooting of European hare and you are a landowner/manager, would you be willing to allow a cull on your land?

20. If the government planned and/or supported a cull of European hares, would you support this decision?

\section{Additional comments (OPTIONAL):}


Biology and Environment

\section{Supplementary information 2}

\section{Management and control of invasive brown hares (Lepus europaeus): contrasting attitudes of selected environmental stakeholders and the wider rural community}

Anthony Caravaggi ${ }^{1,2,3 *}$, W. Ian Montgomery ${ }^{1,2,4}$, Neil Reid $^{1,2,4}$

\footnotetext{
${ }^{1}$ Quercus, School of Biological Sciences, Queen's University Belfast, Belfast, BT9 7BL, UK.

2 School of Biological Sciences, Queen's University Belfast, Belfast, BT9 7BL, UK.

${ }^{3}$ Current address: School of Biological, Earth and Environmental Sciences, University

College Cork, Distillery Field, N Mall, Cork, Ireland

${ }^{4}$ Institute of Global Food Security (IGFS), Queen's University Belfast, Belfast, BT9 5BN, UK.

* Corresponding author: acaravaggi01@qub.ac.uk
} 


\section{Model averaging}

Variance inflation factors (VIF values) between pairs of variables were $\leq 3$ (Zuur et al., 2009) indicating that all could be fitted simultaneously as independent explanatory variables, with the exception of Q20 (VIF = 3.1). Data were standardized to have a $\bar{x}=0$ and $\sigma=1$ prior to analysis, thus permitting the direct comparison of regression coefficients. All possible model permutations were created and ranked according to their Akaike Information Criterion (AIC) values. The Akaike weight $\left(\omega_{i}\right)$ of each model within the top set of $N$ models (i.e. $\Delta$ AIC $\leq 2$; Burnham \& Anderson, 2002) was calculated. The relative importance of each variable within the top set of models was ascertained by calculating $\Sigma \omega_{i}$ (McAlpine et al., 2006), where the higher the value (between 0 and 1), the more important the variable. The effect size (standardised $\beta$ coefficient $\pm \mathrm{SE}$ ) of each variable across the top set of models was determined via multimodel inference and model averaging (Burnham \& Anderson, 2002; Fig. S2.1).

\section{References}

Burnham, K. and Anderson, D. 2002 Model selection and multi-model inference: a practical information-theoretic approach. Springer, New York.

McAlpine, C.A., Rhodes, J.R., Callaghan, J.G., Bowen, M.E., Lunney, D., Mitchell, D.L., Pullar, D.V. and Possingham, H.P. 2006 The importance of forest area and configuration relative to local habitat factors for conserving forest mammals: A case study of koalas in Queensland, Australia. Biological Conservation 132, 153-165.

Zuur, A.F., Ieno, E.N. and Walker, N. 2009 Mixed effects models and extensions in ecology with $R$. Springer New York. 


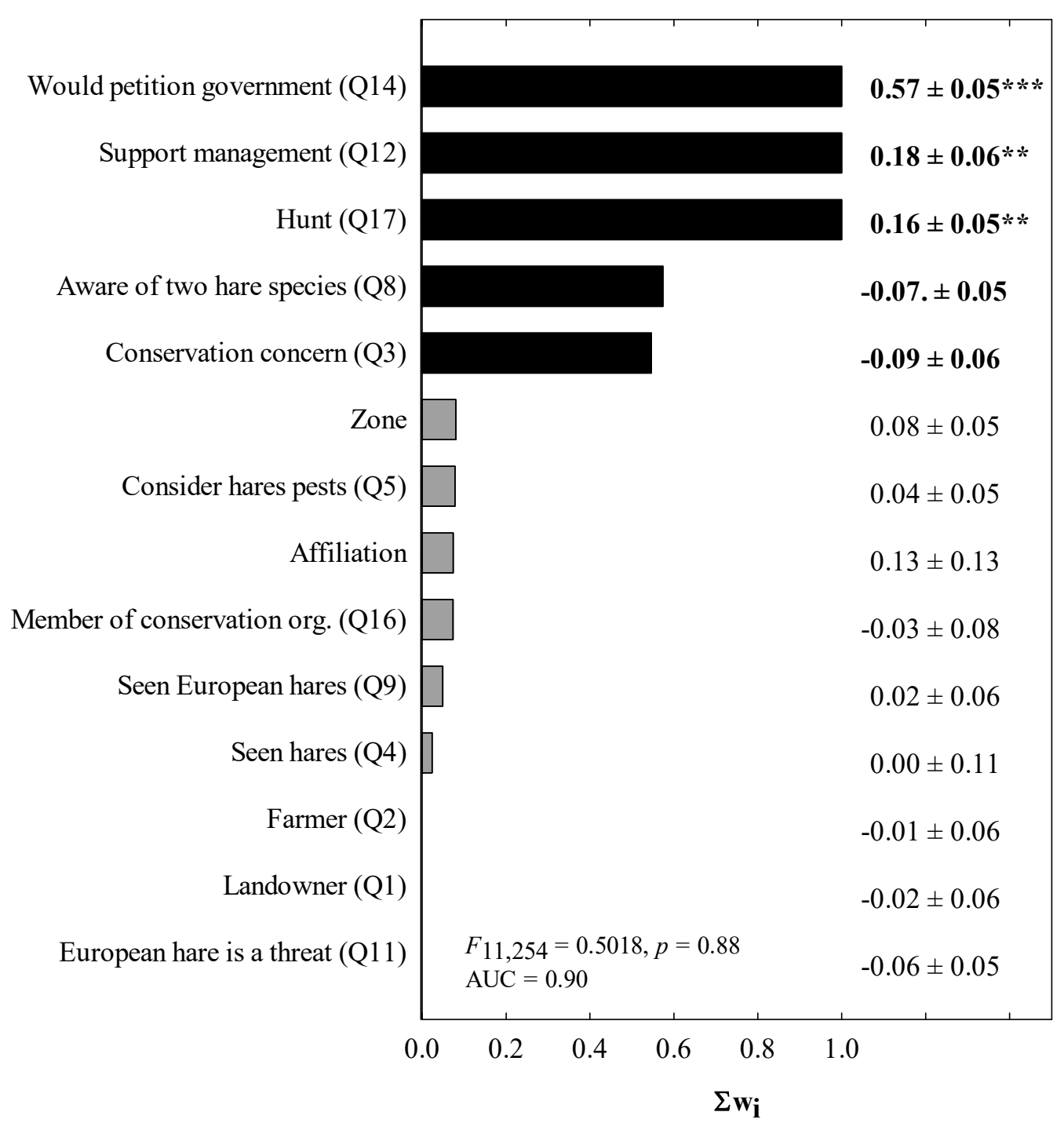

Fig. S2.1. Relative importance of explanatory variables in explaining support of lethal management of the European hare in Northern Ireland. Variables within the top set of models $(\Delta \mathrm{AIC} \leq 2)$ were ranked according to the sum of their Akaike weights $\left(\Sigma \omega_{i}\right)$. Black bars indicate variables which were retained in the best single approximating model; grey bars indicate variables included in all other top-set models. Standardised $\beta$ values \pm standard errors are given; $p$ values are denoted as $* p<0.05$, ** $p<0.01$, and $* * * \quad p<0.001$. Question numbers are given in parentheses (see Supplementary Information 1 for full text). Affiliation describes respondent group (i.e. Countryside Alliance Ireland [CAI] member, or non-member) and Zone describes respondent location (i.e. within the invasive species core range, invasive species peripheral range or native species allopatry). 
Biology and Environment

\section{Supplementary information 3}

\section{Management and control of invasive brown hares (Lepus europaeus): contrasting attitudes of selected environmental stakeholders and the wider rural community}

Anthony Caravaggi ${ }^{1,2,3 *}$, W. Ian Montgomery ${ }^{1,2,4}$, Neil Reid $^{1,2,4}$

\footnotetext{
${ }^{1}$ Quercus, School of Biological Sciences, Queen's University Belfast, Belfast, BT9 7BL, UK.

2 School of Biological Sciences, Queen's University Belfast, Belfast, BT9 7BL, UK.

${ }^{3}$ Current address: School of Biological, Earth and Environmental Sciences, University

College Cork, Distillery Field, N Mall, Cork, Ireland

${ }^{4}$ Institute of Global Food Security (IGFS), Queen's University Belfast, Belfast, BT9 5BN, UK.

*Corresponding author: acaravaggi01@qub.ac.uk;
} 
Selected additional comments provided by questionnaire respondents. Some comments have been edited for brevity.

\section{Countryside Alliance Ireland members:}

\section{Reasons for hare declines:}

- "Over the last 60 years European and Irish hares have both become scarce in this area. Their decrease is a result of big changes in agricultural practise - heavier grazing and early silage cutting."

- "Hare are no longer common in my area. Too many predators and early silage cutting."

- "The threat to the Irish hare comes from slurry sprayed on land and domestic cats kills all the young."

- "The reason for the decline in hare population is the whole country is overrun with vermin: mink, buzzards, pine marten, stoats, rats, magpies, crows, buzzards, foxes."

Reasons for increases hare numbers:

- "On land controlled for shooting, making it more wildlife friendly, we have seen hare numbers increase slightly."

Against a cull:

- "I do not believe this to be true. The European hare is not a threat. They favour different types of ground."

- "Government culls tend to be very expensive. Would rather see money spent on habitat improvement and conservation of Irish hare / containment of European."

- "There needs to be a law passed to ban lamping at night-time... If you are going to cull the European hare, are you going to replace with the Irish hare?"

- "There is a hunt club in my area and I would not like to shoot hares as it would harm the huntmen's sport."

Concerns regarding species identification:

- "Concerned that the wrong hare would be shot. Identification would have to be accurate."

- "I would be very afraid that when word of a cull became common knowledge, it would result in the death of some Irish hares."

- "I would fully support an action plan to promote and conserve native Irish hare numbers but I feel that shooting is the wrong answer. It can be difficult to differentiate between the Irish hare and European hare unless up close and with practise." 


\section{Non-members:}

\section{Reasons for hare declines:}

- "50 years ago we had a large number of European brown \& Irish hares. Over the last ten years, hares have disappeared totally from our area. I would blame this on the increase of foxes and buzzards."

- "Cut down birds of prey and foxes to get the population of hares to rise."

- "I do not think the European hare is a threat to Irish hares. I believe a bigger threat is foxes and crows."

\section{Reactions to information sheet:}

- "I would like to know more about a cull before I would be comfortable with it. Your article was very informative."

- "I was unaware of the two species of hare until the survey."

Concerns regarding culls:

- "I would like to see the native hare preserved but would need much greater detail and evidence before actively supporting a cull."

- "If there was strong evidence of the European hare posing a significantly negative effect on the Irish hare then we would re-think my position on a cull."

- "I am sensitive about hurting animals, but I do understand the need to save the species."

- "I am not convinced European hares pose a risk to the native species. I find hare populations to be low on my farm. I find culling a cruel method of control, shooting or otherwise, as it impacts on offspring which may inhabit forms and can starve after the death of the adult."

Regarding (invasive) species management:

- "Would you cull all the other invasive species? Mink, grey squirrel, ferret, etc."

- "If the non-native hares can be trapped, why kill them? There must be other parts of Europe where they are in decline. Why not work with other conservation groups to reintroduce them? Cull shows limited and insular thinking."

- "In my opinion it is not hares that are the problem, it is rabbits."

- "Better any hare than none at all."

- "Farmers should be doing better management of their lands for the betterment of the Irish hare." 